\title{
Síndrome congênita pelo vírus zika: análise das redes de apoio de pais
}

Congenital zika syndrome: analysis of parent support networks Síndrome congénito por el virus del zika: análisis de las redes de apoyo de padres

Roama Paulo Ulisses Vaz da Costa ${ }^{1}$ @i htps://orcid.org/0000-0003-4947-9705

Zeni Carvalho Lamy ${ }^{1}$ ( ) nttps://orcid.orgy/0000-0002-9332-0542

Poliana Soares de Oliveira ${ }^{1}$ ic https://orcid.org/0000-0003-3596-0194

Ruth Helena de Souza Britto Ferreira de Carvalho' ${ }^{1}$ ib https://orcid.org/0000-0003-1180-1586

Marina Uchoa Lopes Pereira ${ }^{1}$ ic nttps://orcid.org/0000-0001-7999-9096

Carolina Nivea Moreira Guimarães ${ }^{1,2}$ io https://orcid.org/0000-0002-0489-1301

Rosangela Fernandes Lucena Batista ${ }^{1}$ ib https:/orcid.org/0000-0002-1529-0165

Maria do Desterro Soares Brandão Nascimento' io https://orcid.org/0000-0003-2783-362X

Como citar: UM, Guimarães CN, et al. Síndrome congênita pelo vírus zika: análise das redes de apoio de pais. Acta Paul Enferm. 2022;35:eAPE02912.

DOI

http://dx.doi.org/10.37689/acta-ape/2022A002912

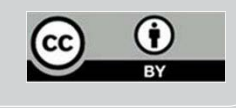

Descritores

Família; Pais; Microcefalia; Infecção por zika vírus; Apoio social

Keywords Family; Parents; Microcephaly; Zika virus infection; Social support

Descriptores Familia; Padres; Microcefalia; Infección por el virus zika; Apoyo social

Submetido 4 de Outubro de 2020 Aceito 26 de Maio de 2021

Autor correspondente Marina Uchoa Lopes Pereira E-mail: ulpmarina@gmail.com

Editor Associado (Avaliação pelos pares): (https://orcid.org/0000-0002-1408-196X) Escola Paulista de Enfermagem, Universidade Federal de São Paulo, São Paulo, SP, Brasil

\section{Resumo}

Objetivo: Compreender o papel das redes de apoio no cuidado de crianças acometidas pela Síndrome Congênita pelo Vírus Zika.

Métodos: Estudo qualitativo, realizado em Centro de Referência Estadual em Neurodesenvolvimento, no nordeste brasileiro, entre abril de 2017 e fevereiro de 2018. Participaram pais de crianças com microcefalia atendidos no local. Foram realizadas 18 entrevistas semiestruturadas, sendo três com pai e mãe e 15 somente com mães, totalizando 21 participantes. A amostra foi definida pelo critério de saturação e foi utilizada análise de conteúdo na modalidade temática.

Resultados: Os resultados são apresentados a partir das categorias de análise "rede informal" e "rede formal". A rede de apoio informal, especialmente os avós, exerceu importante suporte emocional e financeiro aos pais. As redes sociais virtuais se destacaram como espaço de compartilhamento de informações e experiências. Quanto à rede de apoio formal, as famílias estabeleceram vínculos mais fortes com profissionais da atenção especializada que ofertaram suporte técnico e acolhimento aos pais e às crianças. Já a atenção primária desempenhou mais o papel de encaminhamento para a atenção especializada. Foram relatados diferentes graus de resolutividade por parte dos municípios, em termos de programas, de atuação de gestores e de profissionais.

Conclusão: As redes informais e formais atuaram de modo complementar no tratamento e apoio às crianças com Síndrome Congênita pelo Vírus Zika. A inserção em diferentes redes informais possibilitou apoio social para enfrentar 0 impacto provocado pela doença. Apesar do investimento do Ministério da Saúde na atenção primária foi identificada fragilidade neste nível de atenção.

\section{Abstract}

Objective: To understand the role of support networks in the care of children affected by Congenital Zika Syndrome.

Methods: This is a qualitative study, conducted at a State Reference Center on Neurodevelopment, in northeastern Brazil, between April 2017 and February 2018. Parents of children with microcephaly treated at the site participated. 18 semi-structured interviews were conducted, three with father and mother and 15 only with mothers, totaling 21 participants. The sample was defined by the saturation criterion and content analysis was used in the thematic modality.

Results: The results are presented from the categories of analysis "informal network" and "formal network". The informal support network, especially grandparents, exercised important emotional and financial support to parents. Virtual social networks stood out as a space for sharing information and experiences. Regarding the 
formal support network, the families established stronger bonds with specialized care professionals who offered technical support and care to parents and children. Primary care, on the other, played the role of referral to specialized care. Different degrees of resolution were reported by the municipalities, in terms of programs, the performance of managers and professionals.

Conclusion: Formal and formal networks acted in a complementary way in the treatment and support of children with Congenital Zika Syndrome. The insertion in different indirect networks allowed social support to face the impact caused by the disease. Despite the ministry of health's investment in primary care, fragility was identified in this level of care.

\section{Resumen}

Objetivo: Comprender el papel de las redes de apoyo en el cuidado de niños afectados por el síndrome congénito por el virus del zika.

Métodos: Estudio cualitativo, realizado en un Centro de Referencia Regional en Neurodesarrollo, en el nordeste brasileño, entre abril de 2017 y febrero de 2018. Participaron padres de niños con microcefalia atendidos en el lugar. Se realizaron 18 entrevistas semiestructuradas, de las cuales tres fueron con el padre y la madre y 15 solo con madres, un total de 21 participantes. La muestra fue definida por el criterio de saturación y se utilizó análisis de contenido en la modalidad temática.

Resultados: Los resultados se presentan a partir de las categorías de análisis "red informal" y "red formal". La red de apoyo informal, especialmente los abuelos, ejerció un importante soporte emocional y financiero para los padres. Las redes sociales virtuales se destacaron como un espacio para compartir información y experiencias. Respecto a la red de apoyo formal, las familias establecieron vínculos más fuertes con profesionales de la atención especializada, que ofrecieron soporte técnico y acogida a los padres y a los niños. Por otro lado, la atención primaria cumplió más el papel de derivar a la atención especializada. Se relataron diferentes niveles de resolución de problemas por parte de los municipios, en términos de programas, de actuación de gestores y de profesionales.

Conclusión: Las redes informales y formales actuaron de modo complementario en el tratamiento y apoyo a niños con síndrome congénito por el virus del zika. La inserción en diferentes redes informales permitió un apoyo social para enfrentar el impacto provocado por la enfermedad. A pesar de las inversiones en atención primaria del Ministerio de Salud, se identificó fragilidad en este nivel de atención.

\section{Introdução}

Em 2015 foi confirmada a circulação do vírus Zika no Brasil ${ }^{(1)}$ associado à epidemia de crianças diagnosticadas com microcefalia. No ano seguinte, foi decretada emergência sanitária pelo Ministério da Saúde (MS) e pela Organização Mundial da Saúde..$^{(2)}$

A microcefalia altera estrutura e funçáo do sistema neurológico, sendo caracterizada pelo perímetro cefálico menor que dois desvios-padróes abaixo da média para sexo e idade gestacional. ${ }^{(3)}$ Atrasos no desenvolvimento neuropsicomotor podem estar associados à microcefalia em variados graus de comprometimento. Quando ocasionada pelo vírus Zika, pode apresentar-se isolada ou parte da Síndrome Congênita pelo Vírus Zika (SCVZ), resultando em baixa qualidade e expectativa de vida. ${ }^{(4,5)}$

Frente ao nascimento de criança portadora de doença com risco para sua vida e desenvolvimento, os pais enfrentam dificuldades, medos e incertezas. Um fator agravante da SCVZ foi que era doença ainda desconhecida, destacada pela mídia. Houve intensa divulgação de informaçôes, frequentemente pouco esclarecedoras, incluindo imagens de crianças com microcefalia. A realidade enfrentada pelos pais e o desencontro de informaçóes geraram necessidade de apoio. As famílias procuraram, então, os serviços de saúde em busca de cuidado e explicaçóes e, também, de outros pais na mesma situação. ${ }^{(1,6)}$

A epidemia trouxe desafios ao sistema de saúde, principalmente considerando os vazios assistenciais já existentes na rede, que não estava preparada para suprir essa nova demanda. ${ }^{(7)} \mathrm{A}$ alta prevalência da doença, a gravidade e cronicidade dos casos, provocaram a necessidade de resposta ágil do Estado com açōes principalmente relacionadas à assistência social e saúde, como benefícios, isenção de impostos, exames e medicamentos. ${ }^{(8)}$

Cuidar de crianças com doença pouco conhecida desencadeia mudanças na rotina familiar, necessitando a reorganizaçâo da vida. ${ }^{(9)}$ A SCVZ atingiu muitas famílias que já viviam em situação de vulnerabilidade, que foi agravada pela doença. ${ }^{(10-12)}$

$\mathrm{O}$ conhecimento da organização e interação entre membros destas famílias, suas formas de cooperação e resolução de problemas, assim como sua aproximação com os serviços e profissionais de saúde são fundamentais para a compreensão das necessidades e potencialidades do cuidado em saúde, em geral e, particularmente, da enfermagem.

Conhecer a experiência da doença e os desafios provocados pela gravidade e incerteza no futuro destas crianças pode contribuir para o entendimento dos vínculos constituídos, reforçados ou ainda rompidos. ${ }^{(13)}$ 
Este trabalho foi realizado considerando as redes de apoio, constituídas por redes de relaçóes formais e informais. As formais são aquelas estabelecidas com profissionais da saúde e assistência social, já as informais compreendem vínculos familiares ou de amizade com destaque à afetividade. ${ }^{(14,15)}$ Tais redes, por vezes, também provêm suporte material e cognitivo.

Assim, o objetivo do estudo foi compreender o papel das redes de apoio no cuidado de crianças acometidas pela Síndrome Congênita pelo Vírus Zika.

\section{Métodos}

Pesquisa qualitativa com base na teoria compreensiva, que busca compreender e interpretar a ação social, ou seja, o comportamento e os significados atribuídos pelos sujeitos investigados. ${ }^{(16)}$

Estudo realizado entre abril de 2017 e fevereiro de 2018 em Centro de Referência Estadual em Neurodesenvolvimento que oferece tratamento especializado às crianças, incluindo microcefalia decorrente da SCVZ. A instituição presta assistência às crianças acompanhando o desenvolvimento neuropsicomotor e dá suporte aos familiares. Conta com equipe multiprofissional composta por médicos, fisioterapeutas, terapeutas ocupacionais, psicólogos, assistentes sociais e fonoaudiólogos.

Participaram mães e/ou pais, cujos filhos recebiam atendimento no local da pesquisa, sendo identificadas 146 crianças com microcefalia. Para definir a amostra foi construído um quadro contendo condiçôes clínicas das crianças e características sociodemográficas dos pais, com base em dados dos 146 prontuários.

Os parâmetros utilizados para contemplar a diversidade das famílias foram: gravidade da doença; local de residência (capital ou interior), idade das mães, situação conjugal, número de filhos, religião, ocupação, renda e escolaridade, buscando contemplar a diversidade das situaçóes encontradas.

O número final da amostra foi de 18 famílias e foi definido pelo critério de saturação, momento no qual os dados obtidos no campo possibilitam ao pesquisador a compreensão do objeto de estudo, na lógica dos entrevistados. ${ }^{(16)}$
A abordagem inicial com os pais, feita no dia da consulta ou por contato telefônico, foi previamente autorizada e mediada pela instituição, considerando que não havia relação anterior com a pesquisadora. Este contato buscou informar sobre a pesquisa, fazer o convite para participação e agendar um encontro na próxima consulta da criança para realização das entrevistas. Não houve recusas.

A técnica de coleta de dados foi a entrevista semiestruturada realizada a partir da seguinte questáo norteadora: qual o papel das redes de apoio no cuidado de crianças acometidas pela SCVZ? Foi utilizado roteiro com questóes abertas relacionadas ao apoio recebido nos cuidados com o filho: de quem recebia apoio, como era esse apoio e sentimentos relacionados. As entrevistas foram realizadas pela pesquisadora principal, em salas privativas, com duração média de 37 minutos, audiogravadas e posteriormente transcritas.

Foi realizada análise de conteúdo na modalidade temática. ${ }^{(16)}$ A pré análise consistiu em leitura flutuante e exaustiva na busca das ideias centrais - unidades temáticas. A sistematização do material se deu a partir de duas categorias analíticas centrais: rede de apoio informal e rede de apoio formal. Os códigos e unidades temáticas identificados no processo de categorização da rede informal foram: ausência de rede, companheiro, familiares, amigos e redes sociais virtuais; e da rede formal: ausência de rede, gestores municipais, estaduais e federais, profissionais da saúde e assistência social.

A pesquisa foi aprovada pelo Comitê de Ética em Pesquisa com seres humanos, parecer $\mathrm{n}^{\mathrm{o}}$ 2.111.125, obedecendo à Resolução 466/12, do Conselho Nacional de Saúde (CNS). A assinatura do Termo de Consentimento Livre e Esclarecido foi realizada previamente à entrevista. Para preservar a identidade dos participantes foram atribuídos nomes fictícios.

\section{Resultados}

Foram realizadas 18 entrevistas, sendo três com pai e mãe e 15 somente com mães. As mães eram as cuidadoras principais em todas as situaçôes. 
Quadro 1. Características sociodemográficas dos entrevistados

\begin{tabular}{|c|c|c|c|c|c|c|c|c|c|c|c|c|c|}
\hline Filho de* & $\begin{array}{l}\text { Entrevista } \\
\text { com }\end{array}$ & $\begin{array}{l}\text { Idade } \\
\text { mãe }\end{array}$ & $\begin{array}{c}\text { Idade } \\
\text { pai }\end{array}$ & $\begin{array}{l}\text { Renda } \\
\text { (SM) }\end{array}$ & $\begin{array}{l}\text { ESC } \\
\text { pai }\end{array}$ & $\begin{array}{l}\text { ESC } \\
\text { mãe }\end{array}$ & Ocupação pai & 0cupação mãe & Situação conjugal & Residência & Religião** & $\begin{array}{l}\text { Gravidez } \\
\text { planejada }\end{array}$ & $\begin{array}{l}N^{\circ} \\
\text { filhos }\end{array}$ \\
\hline Moana & Mãe & 30 & - & 1,5 & - & EFC & - & Do lar & Casada & INT & - & Não & 4 \\
\hline Marina & Mãe & 18 & 31 & 1 & EFI & EFI & Sem emprego & Autônoma & União consensual & CAP & Evangélica & Sim & 2 \\
\hline Mônica & Mãe & 21 & 28 & 1 & EMC & EMC & Sem emprego & Do lar & Casada & CAP & Evangélica & Não & 3 \\
\hline Melissa & Mãe & 18 & 21 & 2 & EMI & EMI & Vendedor & Do lar & Casada & INT & Católica & Não & 1 \\
\hline Marcela & Casal & 35 & 29 & 2 & EMC & EFC & Vendedor & Do lar & Casada & INT & Evangélica & Não & 5 \\
\hline Maria & Casal & 21 & 26 & 2 & EMC & EFC & Vigilante & Do lar & Casada & INT & Evangélica & Sim & 3 \\
\hline Márcia & Casal & 22 & 28 & 1 & EFC & $\mathrm{Sl}$ & Sem emprego & Estudante & União consensual & INT & & Sim & 1 \\
\hline Mary & Mãe & 20 & 22 & 1,5 & $\mathrm{EFC}$ & EMC & Pintor & Do lar & União consensual & INT & Católica & Não & 2 \\
\hline Milena & Mãe & 31 & 37 & 3 & EMC & SC & Comerciante & Do lar & Casada & INT & Sem religião & Sim & 2 \\
\hline Mariana & Mãe & 22 & 24 & 1,5 & EMC & EFC & Sem emprego & Do lar & União consensual & CAP & - & Não & 3 \\
\hline Maísa & Mãe & 42 & 37 & 1 & $\mathrm{EFI}$ & $\mathrm{EFI}$ & Autônomo & Do lar & Separados & CAP & - & Não & 9 \\
\hline Michele & Mãe & 19 & 24 & 1,5 & $\mathrm{EFI}$ & EMC & Sem emprego & Do lar & Casados & INT & Católica & Não & 1 \\
\hline Marisa & Mãe & 32 & 37 & 1,5 & EMC & EMC & Sem emprego & Do lar & Casados & CAP & Evangélica & Não & 2 \\
\hline Mel & Mãe & 20 & 22 & 1 & EMC & SC & Vendedor & Do lar & União consensual & INT & Evangélica & Sim & 3 \\
\hline Matilde & Mãe & 26 & 16 & 2 & $\mathrm{SI}$ & EMC & Recepcionista & Do lar & Namorados & CAP & Católica & Não & 1 \\
\hline Mirian & Mãe & 39 & 42 & 1 & $\mathrm{EFI}$ & EFC & Autônomo & Do lar & Viúva & INT & - & Sim & 2 \\
\hline Melani & Mãe & 15 & 26 & 3,5 & EMC & EMC & Autônomo & Do lar & União consensual & CAP & Católica & Não & 1 \\
\hline Mila & Mãe & 20 & 35 & 1 & EMC & EMC & Autônomo & Vendedor & União consensual & INT & - & Não & 1 \\
\hline
\end{tabular}

SM - Salário mínimo; ESC - Escolaridade; EFI - Ensino Fundamental Incompleto; EFC - Ensino Fundamental Completo; EMI - Ensino Médio Incompleto; EMC - Ensino Médio Completo; SC - Ensino Superior Completo; SI Ensino Superior Incompleto; INT - Interior; CAP - Capital; ${ }^{\star}$ Nome fictício; ${ }^{\star}$ Religião dos entrevistados

A maioria das mulheres vivia com o companheiro; tinha dois ou mais filhos e não planejou a gravidez. Duas relataram nova gravidez no início da pesquisa, assim, as crianças com SCVZ eram os filhos mais novos em 16 casos.

As mães tinham entre 15 e 42 anos e, seus companheiros, entre 26 e 42. A escolaridade variou de ensino fundamental incompleto até ensino superior completo. A maioria das famílias tinha renda inferior a dois salários mínimos e, em cinco, a renda principal era o Benefício Assistencial de Prestação Continuada (BPC). A maioria dos entrevistados morava no interior do estado (Quadro 1).

Das crianças, onze eram do sexo feminino. Tinham idade entre 11 e 23 meses (Quadro 2). Todas tinham o fenótipo característico da SCVZ. As comorbidades mais presentes foram epilepsia e visão subnormal (Quadro 3).

A análise dos relatos partiu das categorias "rede de apoio informal" e "rede de apoio formal". Em cada categoria foram identificadas a presença ou ausência de redes de apoio e suas consequências para a dinâmica familiar e para o cuidado da criança.

\section{Redes de apoio informal}

Com exceção de uma mãe, os entrevistados declararam possuir alguma rede de apoio informal. Foram
Quadro 2. Características das crianças com Síndrome Congênita pelo Vírus Zika

\begin{tabular}{|c|c|c|c|c|c|}
\hline Filho de ${ }^{*}$ & Sexo & Idade & $\begin{array}{c}\text { Local de } \\
\text { nascimento }\end{array}$ & $\begin{array}{l}\text { Momento do } \\
\text { diagnóstico }\end{array}$ & $\mathrm{PC}(\mathrm{cm})$ \\
\hline Moana & $\mathrm{F}$ & $1 \mathrm{a} 5 \mathrm{~m}$ & Município do interior & Ao nascer & 27 \\
\hline Marina & $\mathrm{F}$ & $1 \mathrm{a} 4 \mathrm{~m}$ & Capital do estado & Gestação & 24 \\
\hline Mônica & $\mathrm{F}$ & $1 \mathrm{a} 5 \mathrm{~m}$ & Capital do estado & Trabalho de parto & 29 \\
\hline Melissa & $\mathrm{F}$ & $1 \mathrm{a} 3 \mathrm{~m}$ & Município do interior & Ao nascer & 28 \\
\hline Marcela & $\mathrm{F}$ & $1 \mathrm{a} 7 \mathrm{~m}$ & Município do interior & Após nascimento $-2 \mathrm{~m}$ & 28 \\
\hline Maria & M & $1 \mathrm{a} 7 \mathrm{~m}$ & Município do interior & Após nascimento - 15d & 27 \\
\hline Márcia & $\mathrm{F}$ & $1 \mathrm{a} 4 \mathrm{~m}$ & Município do interior & Ao nascer & 28 \\
\hline Mary & $\mathrm{F}$ & $1 \mathrm{a} 4 \mathrm{~m}$ & Capital do estado & Gestação & 26 \\
\hline Milena & M & $1 \mathrm{a} 4 \mathrm{~m}$ & Município do interior & Após nascimento - 11d & 28 \\
\hline Mariana & M & $1 \mathrm{a} 6 \mathrm{~m}$ & Capital do estado & Ao nascer & 28 \\
\hline Maísa & $\mathrm{F}$ & $1 \mathrm{a} 1 \mathrm{~m}$ & Capital do estado & Após nascimento $-2 \mathrm{~m}$ & 33 \\
\hline Michele & M & $11 \mathrm{~m}$ & Município do interior & Após nascimento - 8m & 30 \\
\hline Marisa & M & $1 \mathrm{a} 9 \mathrm{~m}$ & Capital do estado & Após nascimento $-7 \mathrm{~m}$ & 29 \\
\hline Mel & $\mathrm{F}$ & $1 \mathrm{a} 9 \mathrm{~m}$ & Município do interior & Gestação & 31,5 \\
\hline Matilde & $\mathrm{F}$ & $1 \mathrm{a} 10 \mathrm{~m}$ & Capital do estado & Após nascimento $-8 \mathrm{~m}$ & 31 \\
\hline Mirian & M & $1 \mathrm{a} 11 \mathrm{~m}$ & Município do interior & Após nascimento & 30,5 \\
\hline Melani & $\mathrm{F}$ & $1 \mathrm{a} 8 \mathrm{~m}$ & Capital do estado & Gestação & 26,5 \\
\hline Mila & $M$ & $1 \mathrm{a} 11 \mathrm{~m}$ & Capital do estado & Gestação & 32 \\
\hline
\end{tabular}

M - Masculino; F - Feminino; d - dias; $\mathrm{m}$ - meses; a - anos; PC - Perímetro Cefálico; *Nome fictício

citados o companheiro, familiares, amigos e contatos realizados por redes virtuais. Nesta pesquisa, nove mulheres demonstraram a parceria do casal no enfrentamento da situação, destacando sua importância nos cuidados do filho.

" $E$ ai, a gente foi se confortando um ao outro" (Melissa)

"Eu e ele o tempo todo" (Marina) 
Quadro 3. Comorbidades das crianças com Síndrome Congênita pelo Vírus Zika

\begin{tabular}{|c|c|c|c|c|c|c|c|}
\hline Filho de* & Comorbidades & $\begin{array}{l}\text { Desproporção } \\
\text { crânio face }\end{array}$ & $\begin{array}{c}\text { Depressão } \\
\text { biparietal }\end{array}$ & $\begin{array}{c}\text { Occipto } \\
\text { proeminente }\end{array}$ & $\begin{array}{l}\text { Excesso de pele } \\
\text { nucal }\end{array}$ & $\begin{array}{l}\text { Pé torto } \\
\text { congênito }\end{array}$ & $\begin{array}{c}\text { Fenda palatina/ } \\
\text { lábio leporino }\end{array}$ \\
\hline Moana & Microcefalia, epilepsia, hidrocefalia, hipertrofia adenoide & Sim & Sim & Sim & Sim & Sim & Não \\
\hline Marina & Microcefalia, visão subnormal & Sim & Sim & Sim & Sim & Não & Não \\
\hline Mônica & Microcefalia, epilepsia & $\operatorname{Sim}$ & Sim & Sim & $\operatorname{Sim}$ & $\operatorname{Sim}$ & Não \\
\hline Melissa & Microcefalia, epilepsia, visão subnormal & Sim & Sim & Sim & Sim & $\operatorname{Sim}$ & Não \\
\hline Marcela & Microcefalia, epilepsia & Sim & Sim & Sim & $\operatorname{Sim}$ & Não & Não \\
\hline Maria & Microcefalia, epilepsia, desnutrição proteico calórica & Sim & Sim & Sim & $\operatorname{Sim}$ & Não & Não \\
\hline Márcia & Microcefalia, crise convulsiva & $\operatorname{Sim}$ & Sim & Sim & Não & $\operatorname{Sim}$ & Não \\
\hline Mary & Microcefalia, úvula bifida, crise convulsiva & $\operatorname{Sim}$ & Sim & Sim & $\operatorname{Sim}$ & Não & Não \\
\hline Milena & microcefalia, epilepsia & Sim & Sim & Sim & Sim & Não & Não \\
\hline Mariana & Microcefalia, ptiríase versicolor, epilepsia & Sim & Sim & Sim & Sim & $\operatorname{Sim}$ & Não \\
\hline Maísa & Sem informação & Sim & Sim & Sim & $\operatorname{Sim}$ & Não & Não \\
\hline Michele & Microcefalia, ptiríase versicolor & $\operatorname{Sim}$ & Sim & Sim & Não & Não & Não \\
\hline Marisa & Microcefalia, paralisia cerebral & Sim & Não & Não & Não & Não & Não \\
\hline Mel & Microcefalia, crise convulsiva, visão subnormal & Sim & Sim & Não & Não & Não & Não \\
\hline Matilde & Microcefalia & Sim & Não & Não & Não & Não & Não \\
\hline Mirian & Microcefalia, epilepsia, derrame pericárdico & Sim & Não & Não & Não & Não & Não \\
\hline Melani & Microcefalia, epilepsia, hidrocefalia & Sim & Sim & Sim & $\operatorname{Sim}$ & $\operatorname{Sim}$ & Não \\
\hline Mila & Microcefalia, epilepsia, visão subnormal & Sim & Sim & Sim & Sim & Sim & Não \\
\hline
\end{tabular}

${ }^{*}$ Nome fictício

Em casais que haviam planejado a gravidez e que apresentavam uma relação conjugal mais estável, os homens participavam mais da divisão das atividades relacionadas aos cuidados com os filhos, proporcionando apoio à mãe, principal cuidadora.

Para algumas mulheres, um pai que "sabe cuidar” era de alguma forma diferenciado.

\section{"Ele é um pai diferente... Ele sabe cuidar" (Moana)}

Outro importante apoio relatado foi o suporte material e emocional recebido pelos seus pais, os avós da criança, especialmente a avó materna.

"E minha mãe [avó materna] sempre do meu lado" (Mary)

"E ele [avô paterno] mandou depositar na nossa conta" (Márcia)

"Com todos ao redor náo tinha nem tempo para pensar em coisa ruim” (Mônica)

As mães também relataram o suporte recebido por seus outros filhos.

"Ele brinca com o irmão enquanto eu preciso fazer algo" (Manuela)
Outro resultado encontrado foi o apoio recebido em grupo de conversa por aplicativo. Foi criado um grupo por pais no início da epidemia, ainda ativo na ocasiáo da pesquisa, com o objetivo de troca de informaçóes e experiências.

\section{"Eu me abracei a esse grupo" (Maria)}

Os pais procuraram dois tipos de informaçóes: as científicas, oferecidas pelos profissionais de saúde e aquelas baseadas em vivências compartilhadas por familiares e grupos virtuais.

Uma mãe declarou não ter apoio. Maísa morava com o companheiro na casa da sogra, mas mudou-se com a filha que chorava muito e incomodava a todos. O parceiro não a acompanhou, permanecendo na outra casa. Além de sozinha, Maísa relatou que os demais filhos, adultos com famílias constituídas, só a procuravam para pedir ajuda financeira e solicitar cuidados com seus próprios filhos.

\section{"Não tenho o apoio de ninguém" (Maísa)}

Apesar do cansaço e de uma narrativa carregada de insatisfação, Maísa falava com esperança sobre planos futuros de melhorias na casa para proporcionar bem-estar para sua filha. 


\section{Redes de apoio formal}

As redes de apoio formal incluíram gestores municipais, estaduais e federais, profissionais da saúde e assistência social.

Com relação à organização da rede no interior do Estado, foram descritos, nas entrevistas, diferentes graus de resolutividade municipal, em termos de programas e de atuação de gestores e profissionais. Em oito entrevistas foi relatada visão positiva com relação à organização da rede:

"Ela [funcionária da Secretaria Municipal de Saúde] consegue tudo pra mim" (Maria)

A (des)organização da rede no interior do Estado, segundo relatos de onze entrevistados, remete à falta de orientaçóes quanto aos programas de assistência ao portador de necessidades especiais, pouca resolutividade na assistência e a necessidade de mediação judicial para garantia de atendimento e tratamento.

\section{"Na minha cidade não tem tratamento" (Moana)}

"Na minha cidade tem tudo: fonoaudiólogo, fisioterapeuta, médico, enfermeiro, mas nunca foram acompanhar" (Marcela)

\section{"Quase todo mês tenho que ir atrás da promotoria" (Maria)}

A Atenção Primária à Saúde (APS) foi citada em apenas uma entrevista. A mãe relatou visita domiciliar realizada pela enfermeira que levou informaçóes sobre cuidados com a criança.

\section{"A enfermeira foi lá em casa e me explicou as coisas direitinho" (Melissa)}

Em 13 casos com acompanhamento do pré-natal na APS, os pais souberam o diagnóstico de microcefalia apenas após o nascimento.

A atuação destes profissionais foi apresentada pelos entrevistados como um passo para o encaminhamento ao tratamento com profissionais especializados. Estes representaram para os pais o suporte terapêutico que tanto necessitavam.

\section{"Ela [médica da atenção especializada] foi todos os profissionais que a gente precisava" (Maria)}

A assistência especializada foi citada em todas as entrevistas com destaque para a infraestrutura e sobretudo o acolhimento e competência dos profissionais.

\section{Discussão}

As redes de apoio informal são compostas por pessoas que fazem parte das relaçóes sociais do indivíduo. Essas redes são fundamentais para o enfrentamento de situaçôes difíceis e contribuem de modo importante para administrar as mudanças exigidas pela doença. Possuem múltiplas dimensóes, a exemplo de vínculos de amizade e suporte familiar e, incluem, por vezes, além ao apoio emocional e cognitivo, também apoio material. ${ }^{(14,15)}$

Historicamente, o cuidado com as crianças foi responsabilidade da mãe, sendo o papel do pai atrelado apenas ao sustento material. A falta de apoio do pai da criança, referida nos resultados, pode ser reflexo dessa construção histórica, sistêmica e enraizada que ainda molda expectativas. Ultrapassá-la é um desafio. ${ }^{(17,18)}$ Ainda que atualmente se observe mudanças, como a participação das mulheres no mercado de trabalho e avanços no conceito de paternidade, o trabalho doméstico e o cuidado dos filhos ainda são majoritariamente desempenhados pelas mulheres. ${ }^{(18,19)}$

Neste sentido, os conceitos de paternidade (que vai além do papel de mantenedor da família) e de paternagem (vinculado à afetividade do pai e à vontade de cuidar) ${ }^{(20)}$ ajudam a compreender distintas formas de conjugalidade. Esta compreensão é importante porque as experiências de maternidade e paternidade, diante do filho com microcefalia por SCVZ, são marcadas pela sobrecarga de cuidados exigidos pela gravidade da doença. ${ }^{(4,21)}$ Pesquisas sobre maternidade e cuidados em tempo de Zika têm destacado o lugar das mães como principais responsáveis pelos cuidados. ${ }^{(9,22-24)}$ A divisão de tarefas com o pai da criança proporcionou às mulheres redução da sobrecarga de trabalho e percepção de acolhimento. 
Como descrito nos resultados, os avós foram citados várias vezes. Em estudo com famílias de crianças com paralisia cerebral, os avós foram reconhecidos como principais fontes de apoio, pois auxiliam de várias formas, inclusive na organização da rotina cansativa de levar regularmente a criança a consultas, o que pode resultar em privação da vida social. ${ }^{(25)}$ As crianças com SCVZ exigem cuidados cotidianos ${ }^{(4,21)}$ e a proximidade da família nestes casos foi bastante valorizada, especialmente da avó materna.

O nascimento de um filho com deficiência é cercado de impactos na rotina familiar. ${ }^{(9,26)}$ As mudanças causadas podem restringir o tempo de convivência dos pais com outros filhos e a atenção dada a eles. Assim como as outras crianças podem, ainda, assumir algumas atividades nos cuidados com o irmão. ${ }^{(27)}$

$\mathrm{O}$ uso das redes sociais virtuais foi outra forma de apoio relatada pelos entrevistados. Estas têm sido um importante espaço para troca de vivências, tanto no cuidado quanto na busca por tratamento. ${ }^{(13)}$ Diante do desafio emocional de criar uma criança com deficiência, o apoio de outros pais permite que a família apreenda melhor as informaçôes compartilhadas, possibilitando a ressignificação de experiências dolorosas. ${ }^{(28)}$

De fato, o convívio em grupos virtuais tem sido relatado como protetor para a qualidade de vida familiar, pois permite o compartilhamento de temáticas do dia-a-dia e, sobretudo, a valorização dos marcos de desenvolvimento das crianças, não focando apenas no adoecimento. ${ }^{(5,29)}$ Além disso, o compartilhamento de experiências e informaçóes recebidas por profissionais e até mesmo as coletadas na internet contribuíram para que se sentissem melhor preparados para o enfrentamento da situação. ${ }^{(13,29)}$

A situação de adoecimento crônico pode contribuir para o fortalecimento ou, ao contrário, para o rompimento dos vínculos familiares. ${ }^{(15)}$ A negação do cuidado à criança ou de sua condição de adoecimento, por familiares, provoca no cuidador principal tristeza e sensação de isolamento. ${ }^{(30)}$ A despeito desse sofrimento, uma participante da pesquisa, que relatou falta de apoio, mencionou que a expectativa de proporcionar bem-estar à filha a encorajava a seguir adiante e a lidar com esta grave situação.
O papel da rede formal foi essencial na epidemia do vírus Zika. O projeto de lei N.o 3.974 de 2015 viabilizou a aposentadoria destas crianças, possibilitando apoio financeiro. ${ }^{(31)}$ No entanto, para que a criança e sua família recebam esses benefícios, a atuação da rede formal é essencial, inclusive com relação ao acesso à informação. ${ }^{(32)}$

A Comissão Intergestores Tripartite aprovou a Portaria Interministerial no 405/MS/MSDA em 2016, que instituiu, no âmbito do Sistema Único de Saúde (SUS), a Estratégia de ação rápida para o fortalecimento da atenção à saúde e da proteção social de crianças com microcefalia, incluindo o direito ao atendimento na atenção primária. ${ }^{(33)}$ Outras propostas de cuidado e capacitação profissional foram criadas pelo MS, visando maior celeridade no diagnóstico e intervenção precoce. ${ }^{(2)}$

$\mathrm{Na}$ tentativa de minimizar seus medos e angústias, os pais buscaram instruçóes sobre como atender às demandas da criança com deficiência, dentre elas, como estimular o desenvolvimento, escolher a melhor educação, contribuir para autonomia do seu filho, lidar com a segurança e direitos da criança. ${ }^{(34)}$

Porém, o direito à informaçáo nem sempre foi garantido. Em pesquisa de mães de crianças com microcefalia foi relatada falta de sensibilidade de profissionais de saúde, que privilegiavam orientaçôes e intervenções sem considerar as demandas familiares, produzindo descrédito na assistência ofertada às crianças. ${ }^{(13)}$

Políticas públicas voltadas às famílias de crianças com necessidades especiais, mesmo quando adequadas às diretrizes de integralidade, universalidade e equidade do SUS, nem sempre criam estratégias que possibilitam a garantia dessa assistência. ${ }^{(35)}$

No plano nacional de enfrentamento do vírus Zika, coube à APS assumir a gestáo do cuidado por meio da puericultura, estimulação precoce, encaminhamento à assistência especializada e identificação das famílias com risco social. A APS compreende açôes que promovem prevenção de agravos, promoção e proteção de saúde, diagnóstico, tratamento, reabilitação, reduçáo de danos e manutenção da saúde. ${ }^{(1)}$ Portanto, tem potencial para ser importante rede de apoio aos pais pela proximidade e conhecimento da realidade enfrentada e de suas deman- 
das imediatas, porém, nesta pesquisa desempenhou principalmente o papel de encaminhamento das crianças para a atenção especializada.

As necessidades provocadas pela epidemia do vírus Zika levaram o Governo do estado em questáo a criar um serviço especializado, que se tornou referência no atendimento e acolhimento de crianças com microcefalia e de seus familiares.

O trabalho compartilhado entre APS e serviço especializado pode contribuir para a redução dos danos causados pela microcefalia. No entanto, a equipe da APS, que deveria coordenar o cuidado em rede, não pareceu desempenhar esse papel essencial junto às crianças com SCVZ. Foi a equipe multiprofissional especializada que representou papel de referência aos pais.

A maioria das entrevistas foi realizada enquanto as mães aguardavam atendimento no centro de referência. Essa pode ter sido uma limitação do estudo, considerando a necessidade de conciliar o tempo da entrevista com o tempo de espera para a consulta. Além disso, a presença da criança e suas necessidades, também eram determinantes da disponibilidade dos cuidadores para a entrevista.

\section{Conclusão}

As redes de apoio informais e formais atuaram de modo complementar no tratamento e apoio aos cuidados de crianças com SCVZ. A rede informal contribuiu significativamente na forma de lidar com a doença. As redes sociais virtuais destacaram-se como novo meio de comunicação que permitiu troca de experiências e compartilhamento de informaçôes entre pais que viviam situaçóes semelhantes. Quanto à rede formal, os municípios do interior do estado apresentaram diferentes graus de resolutividade, evidenciando lacunas na organização da rede assistencial, de modo que os usuários dependiam da atuaçáo individual dos profissionais para conseguir acesso aos serviços e benefícios. Em relação aos profissionais de saúde, os vínculos estabelecidos foram principalmente com a atenção especializada. Com profissionais da APS o compartilhamento e orientação de cuidado para os familiares foi mais intermitente e frágil.

\section{Agradecimentos}

À Coordenação de Aperfeiçoamento de Pessoal de Nível Superior (CAPES), ao Conselho Nacional de Desenvolvimento Científico e Tecnológico CNPq e à Fundação de Amparo à Pesquisa e ao Desenvolvimento Científico e Tecnológico do Maranhão (FAPEMA) pelo financiamento.

\section{Colaborações}

Costa RPUV, Lamy ZC, Soares P, Carvalho RHSBF, Pereira MUL, Guimarães CNM, Batista RFL, Nascimento MDSB contribuíram com a concepção do estudo, análise e interpretação dos dados, redação do artigo e aprovação da versão final a ser publicada.

\section{Referências}

1. Brasil. Ministério da Saúde. Secretaria de Vigilância em Saúde. Virus Zika no Brasil: a resposta do SUS. Brasília (DF): Ministério da Saúde; 2017 [citado 2020 Jul 28]. Disponível em: https://bvsms.saude.gov. br/bvs/publicacoes/virus_zika_brasil_resposta_sus.pdf

2. Brasil. Ministério da Saúde. Secretaria de Vigilância em Saúde. Monitoramento dos casos de dengue, febre de Chikungunya e febre pelo vírus Zika até a Semana Epidemiológica 42 de 2018. Bol Epidemiol. 2018;40(44):1-14.

3. Brasil. Ministério da Saúde. Secretaria de Atenção à Saúde. Protocolo de atenção à saúde e resposta à ocorrência de microcefalia relacionada à infecção pelo vírus Zika. Brasília (DF): Ministério da Saúde; 2016 [citado 2020 Jul 28]. Disponível em https://bvsms.saude.gov.br/bvs/ publicacoes/protocolo_resposta_microcefalia_relacionada_infeccao_ virus_zika.pdf

4. Oliveira PS, Lamy ZC, Guimarães CN, Rodrigues CB, Silva AA, Simões VM, et al. Experiências de pais de crianças nascidas com microcefalia, no contexto da epidemia de Zika, a partir da comunicação do diagnóstico. Cad Saude Publica. 2019;35(12):e00226618.

5. Oliveira MC, SÁ SM. A experiência parental após o diagnóstico da microcefalia por zika vírus: um estudo de caso. Rev Pesqui Fisioter. 2017;7(4):64-70.

6. Bosaipo DS, Lamy ZC, Oliveira PS, Gomes CM, Assis MR, Ribeiro MR, et al. Itinerário terapêutico de crianças com microcefalia pelo vírus zika. Cien Saude Colet. 2019 Ago 30. [Ahead of print].

7. Santos DB, Silva EF, Lima SO, Reis FP, Oliveira CC. Health Care Network: Maternal perception regarding the quality of care to children with microcephaly. Esc Anna Nery. 2019;23(4):e20180335.

8. Barbosa LA, Bem IP. Microcefalia pelo Zika Vírus: as ações dos Poderes Legislativo e Executivo brasileiros no combate à epidemia. Cad IberoAmer Dir Sanit. 2018;7(1):127-46. 
9. Sá SA, Galindo CC, Dantas RS, Moura JC. Dinâmica familiar de criança com a síndrome congênita do Zika vírus no Município de Petrolina, Pernambuco, Brasil. Cad Saude Publica. 2020;36(2):e00246518.

10. Abreu TT, Novais MC, Guimarães IC. Crianças com microcefalia associada a infecção congênita pelo vírus Zika: características clínicas e epidemiológicas num hospital terciário. Rev Ciênc Méd Biol. 2016;15(3):426-33.

11. Almeida LS, Araújo LA, Cota AL, Rodrigues DF. Processos sociais e vulnerabilidades na saúde: comportamento da infecção por zika vírus. Social Questão. 2020;23(48):339-61.

12. Dotta AG, Tomazoni LR. The impact of the ZIKA Virus on the reproductive health of Brazilian women, environmental racism and the action for Direct Control of Unconstitutionality (ADI) No. 5581. Braz J Law Res. 2020;1(2):109-32.

13. Fleischer S. Segurar, caminhar e falar: notas etnográficas sobre a experiência de uma "mãe de micro" no Recife/PE. Cad Gênero Divers. 2017;3(2):93-112.

14. Rosa TE, Benício MH. As redes sociais de apoio: 0 conviver e a sua influência sobre a saúde. Bol Inst Saúde. 2009;(47):80-83.

15. Herzlich C, Adam P. Sociologia da doença e da medicina. Bauru: EDUSC; 2001.

16. Minayo MC. 0 desafio do conhecimento: pesquisa qualitativa em saúde. 14a ed. São Paulo: Hucitec; 2014.

17. Botton A, Cúnico SD, Barcinski M, Strey MN. Os papéis parentais nas famílias: analisando aspectos transgeracionais e de gênero. Pensando Famílias. 2015;19(2):43-56.

18. Lins ZM, Salomão NM, Lins SL, Carneiro TF, Eberhardt AC. 0 papel dos pais e as influências externas na educação dos filhos. Rev SPAGESP. 2015;16(1):43-59.

19. Bernardi D. Paternidade e cuidado: "novos conceitos", velhos discursos. Psicol Rev. 2017;26(1):59-80.

20. Zornig SA. Construção da parentalidade: da infância dos pais ao nascimento do filho. In: Piccinini CA, Alvarenga P. Maternidade e paternidade: a parentalidade em diferentes contextos. São Paulo: Casa do Psicólogo; 2012. p. 17-31.

21. Pedrosa RK, Guedes AT, Soares AR, Vaz EM, Collet N, Reichert AP. Itinerário da criança com microcefalia na rede de atenção à saúde. Esc Anna Nery. 2020;24(3):e20190263.

22. Scott RP, Lira LC, Matos SS, Souza FM, Silva AC, Quadros MT. Itinerários terapêuticos, cuidados e atendimento na construção de ideias sobre maternidade e infância no contexto da Zika. Interface. 2018;22(66):673-84.

23. Moreira $\mathrm{MC}$, Mendes $\mathrm{CH}$, Nascimento M. Zika, protagonismo feminino e cuidado: ensaiando zonas de contato. Interface. 2018;22(66):697708.

24. Vale PR, Alves DV, Carvalho ES. "Very busy": daily reorganization of mothers to care of children with Congenital Zika Syndrome. Rev Gaúcha Enferm. 2020;41:e20190301.
25. Milbrath VM, Soares DC, Amestoy SC, Cecagno D, Siqueira HC. Mães vivenciando o diagnóstico da paralisia cerebral em seus filhos. Rev Gaúcha Enferm. 2009;30(3):437-44.

26. Castro BS, Moreira MC. (Re) conhecendo suas casas: narrativas sobre a desospitalização de crianças com doenças de longa duração. Physis Rev Saúde Coletiva. 2019;28(3):e280322.

27. Woodgate RL, Edwards M, Ripat JD, Rempel G, Johnson SF. Siblings of children with complex care needs: their perspectives and experiences of participating in everyday life. Child Care Health Dev. 2016;42(4):504-12.

28. DeHoff BA, Staten LK, Rodgers RC, Denne SC. The role of online social support in supporting and educating parents of young children with special health care needs in the United States: a scoping review. J Med Internet Res. 2016;18(12):e333. Review.

29. Vuorenmaa M, Halme N, Perälä ML, Kaunonen M, Åstedt-Kurki P. Perceived influence, decision-making and access to information in family services as factors of parental empowerment: a crosssectional study of parents with young children. Scand J Caring Sci. 2016;30(2):290-302.

30. Bolla BA, Fulconi SN, Baltor MR, Dupas G. Cuidado da Criança com anomalia congênita: a experiência da família. Esc Anna Nery. 2013;17(2):284-90.

31. Brasil. Câmara dos Deputados. Projeto de lei n. ${ }^{0} 3.974$, de 2015. Dispõe sobre direito a dano moral e concessão de pensão especial à pessoa com Microcefalia ou com Síndrome de Guillain-Barré, decorrentes do Zika Vírus. Brasilia (DF): Câmara dos Deputados; 2015 [citado 2020 Jul 28]. Disponível em: https://www.camara.leg.br/proposicoesWeb/prop mostrarintegra;jsessionid=1E4761D5ACA3A532108D609F570795BD.propo sicoesWeb2?codteor=1431118\&filename=Avulso+-PL+3974/2015

32. Brunoni D, Blascovi-Assis SM, Osório AA, Seabra AG, Amato CA, Teixeira MC, et al. Microcephaly and other Zika virus related events: the impact on children, families and health teams. Cien Saude Colet. 2016;21(10):3297-302.

33. Brasil. Ministério da Saúde. Portaria n 405, de 15 de março de 2016. Institui, no âmbito do Sistema Único de Saúde (SUS) e do Sistema Único de Assistência Social (SUAS), a Estratégia de Ação Rápida para 0 Fortalecimento da Atenção à Saúde e da Proteção Social de Crianças com Microcefalia. Brasília (DF): Ministério da Saúde; 2016 [citado 2020 Jul 28]. Disponível em: https://www.in.gov.br/materia/-/asset_ publisher/Kujrw0TZC2Mb/content/id/22541437/d01-2016-03-16portaria-interministerial-n-405-de-15-de-marco-de-2016-22541371

34. Piškur B, Beurskens AJ, Ketelaar M, Jongmans MJ, Casparie BM, Smeets RJ. Daily actions, challenges, and needs among Dutch parents while supporting the participation of their child with a physical disability at home, at school, and in the community: a qualitative diary study. BMC Pediatr. 2017;17(1):12.

35. Baltor MR, Matos AP, Wernet M, Ferreira NM, Dupas G. The perceptions of families with children having chronic diseases and their relationships with healthcare professionals. Rev Esc Enferm USP. 2013;47(4):80814. 